\title{
Experiment on an Onsite Early Warning Method for the Taiwan Early Warning System
}

\author{
by Yih-Min Wu and Hiroo Kanamori
}

\section{Introduction}

As increasing urbanization is taking place worldwide, earthquake hazards pose serious threats to lives and property in urban areas. For seismic hazard mitigation, a practical earthquake forecast method appears to be far from realization, because of the extreme complexity involved in earthquake processes (e.g., Kanamori et al., 1997). Another approach to mitigate seismic hazards is the development of early warning systems (EWS) (Nakamura, 1984, 1988; Heaton, 1985; United States National Research Council, 1991; Teng et al., 1997; United States Geological Survey, 1998; Wu et al., 1998; Wu and Teng, 2002; Allen and Kanamori, 2003). An EWS provides a few seconds to tens of seconds of warning time for impending ground motions, allowing for mitigation measures in the short term. Early warning systems that estimate the severity of ground shaking and its onset time are in operation in Japan (Nakamura, 1984, 1988, 1989), Mexico (Espinosa-Aranda et al., 1995), and Taiwan (Teng et al., 1997; Wu et al., 1998, 1999; Wu and Teng, 2002). This timely information can be used to minimize property damage and the loss of lives in urban areas. It can also be used for real-time loss estimation to aid emergency response and recovery (Wu et al., 2002).

Two types of EWS are in operation around the world. One is a front-detection EWS: seismometers installed in the earthquake source area give early warnings to more distant urban areas. Nakamura (1984) introduced the first practical system for the Japanese train system. The Taiwan and Mexico systems are examples of this type. The other is an onsite EWS, which determines the earthquake parameters from the initial portion of the $P$ wave and predicts the more severe ground shakings of the following $S$-wave trains. The urgent earthquake detection and alarm system (UrEDAS) (Nakamura, 1988, 1989) is an example of this type. A prototype system, ElarmS (Allen and Kanamori, 2003) also uses this method.

In most front-detection systems, $S$ waves are used for the determination of earthquake magnitude. While this method provides accurate magnitude determinations, the determination of earthquake parameters has to wait until the arrival of the $S$ waves. For example, the Taiwan Central Weather Bureau (CWB) uses a front-detection system and requires an average of $22 \mathrm{sec}$ to determine earthquake parameters with magnitude uncertainty of \pm 0.25 . It provides a warning for areas beyond about $70 \mathrm{~km}$ from the epicenter. In contrast, UrEDAS and ElarmS both use the predominant period from the initial 2-4 sec of $P$ waves to determine the magnitude for EWS, and the method described by Grecksch and Kumpel (1997) estimates the magnitude from the first second of the $P$ wave recorded on accelerograms. However, large uncertainties in magnitude are inevitable in these methods. For ElarmS, the average absolute error in the magnitude estimate is \pm 0.7 , and when the closest 10 stations are used, the average error drops to \pm 0.35 . Grecksch and Kumpel (1997) estimate magnitudes using the rise time of the first complete peak, the predominant period, and the related Fourier amplitude of the initial part of strong-motion signals. With this approach, the magnitude uncertainty can reach as high as \pm 1.35 with a single accelerogram and \pm 0.5 with more than eight accelerograms.

Taiwan has established several research programs that are actively pursuing earthquake early warning and rapid reporting systems (Teng et al., 1997; Wu et al., 1997, 1998, 1999, 2000, 2001, 2002, 2003; Wu and Teng, 2002, 2004). The Taiwan EWS established by CWB (Fig. 1a) uses a realtime strong-motion accelerograph network consisting of 86 stations distributed around Taiwan. By applying the concept of a virtual subnetwork (VSN) to the CWB seismic network (Wu and Teng, 2002), an optimized solution between earthquake early warning and reliable magnitude determination is sought. This represents a significant step toward realistic earthquake early warning capability. The 22-sec reporting time of the Taiwan EWS will offer earthquake early warnings for metropolitan areas located more than $70 \mathrm{~km}$ from the epicenter. For an event with the same location as the 20 September 1999 Chi-Chi, Taiwan, earthquake, the Taipei metropolitan area, at $145 \mathrm{~km}$ from the epicenter, would have more than $20 \mathrm{sec}$ of early warning time. Figure $1 \mathrm{~b}$ shows the expected early warning times for an event such as the Chi-Chi earthquake for all parts of Taiwan. The small triangles give the locations of elementary schools, which essentially reflect the population density.

The idea of an early warning system presented here takes advantage of the fast data-transmission speed, which is much faster than the seismic-wave speed, and fast dataprocessing speed. However, the Taiwan EWS has a blind zone that gives no warning to target areas closer than $70 \mathrm{~km}$ from the source. To provide early warning to areas close to the source, a complementary use of an on-site EWS is desirable. Recently, Kanamori (2005) extended the method of Nakamura (1988) and Allen and Kanamori (2003) to deter- 
(a)

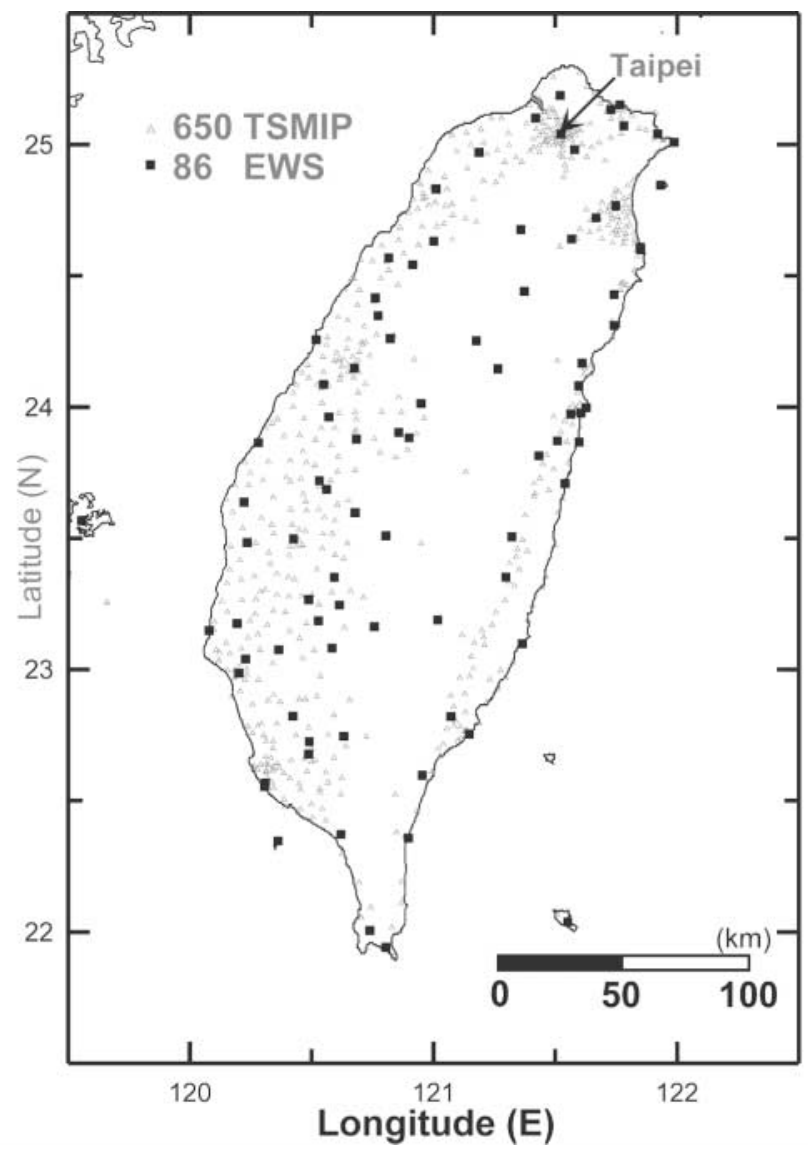

(b)

Early Warning Time of the Earthquake of Sep. 20, 1999 (Mw7.6)

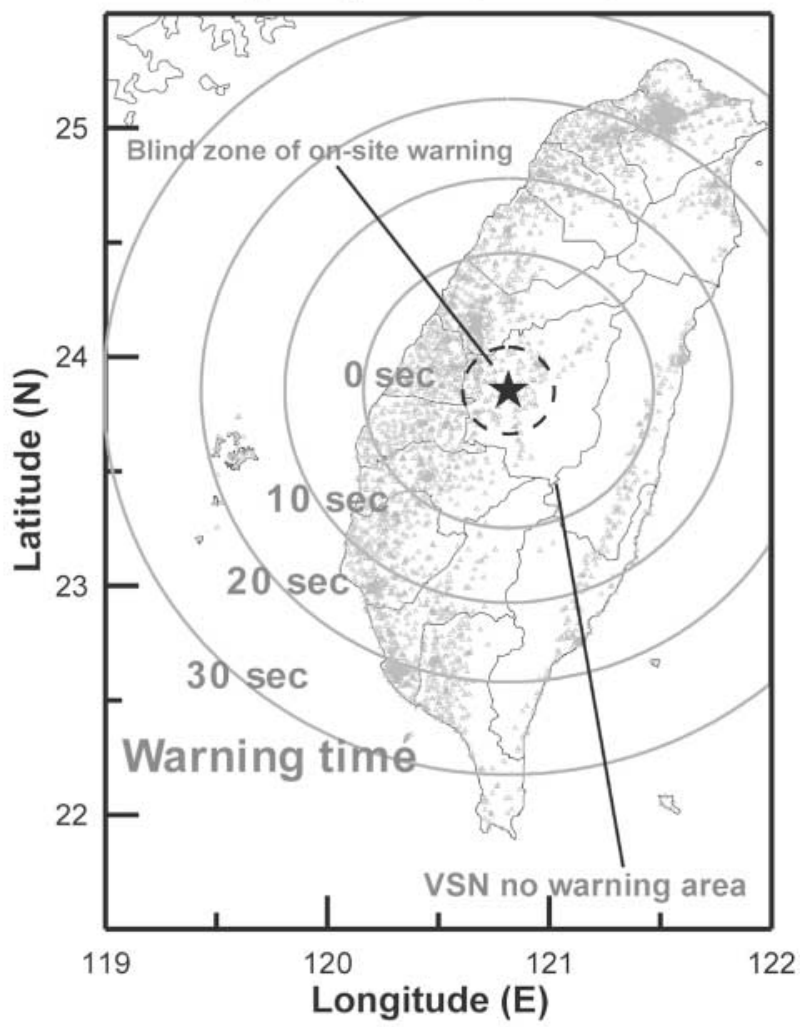

Figure 1. (a) Station distribution of the Taiwan early warning system (EWS) and the Taiwan Strong Motion Instrumentation Program (TSMIP). (b) Expected EWS early warning times (indicated by circles) in Taiwan with respect to the occurrence of an event similar to the Chi-Chi earthquake of 20 September 1999. Small circle (dashed) with a radius of $21 \mathrm{~km}$ indicates the boundary of the blind zone of the on-site warning method. Triangles give the locations of elementary schools, which can be regarded as an indication of the population density of Taiwan.

mine a parameter, called $\tau_{c}$, that reflects the size of an earthquake from the initial $3 \mathrm{sec}$ of the $P$ waves. We have explored the use of this method to complement the frontdetection Taiwan EWS system.

\section{$\tau_{c}$ Method}

To determine the size of an earthquake, it is important to determine whether the event's slip motion has stopped or is still growing, which is generally reflected in the period of the initial motion. Small and large events yield short- and long-period initial motions, respectively. However, the slip motion is in general complex, and even a large event often begins with a small short-period motion, followed by a longperiod motion. Consequently, it is important to define the average period during the first motion, instead of the period of the first motion. The method developed by Nakamura (1988) attempts to use the period averaged over some time window. We use the following procedure, which is modified from the method used by Nakamura (1988). We take the ground-motion displacement, $u(t)$, and velocity, $\dot{u}(t)$, from the vertical component record and compute the following ratio $r$ by

$$
r=\frac{\int_{0}^{\tau_{0}} \dot{u}^{2}(t) d t}{\int_{0}^{\tau_{0}} u^{2}(t) d t},
$$

where the integration is over the time interval $\left(0, \tau_{0}\right)$ after the onset of the $P$ wave. Usually, $\tau_{0}$ is set at $3 \mathrm{sec}$. Using Parseval's theorem,

$$
r=\frac{4 \pi^{2} \int_{0}^{\infty} f^{2}|\hat{u}(f)|^{2} d f}{\int_{0}^{\infty}|\hat{u}(f)|^{2} d f}=4 \pi^{2}\left\langle f^{2}\right\rangle,
$$

where $\hat{u}(f)$ is the frequency spectrum of $u(t)$, and $\left\langle f^{2}\right\rangle$ is the average of $f^{2}$ weighted by $|\hat{u}(f)|^{2}$. Thus, 


\section{Numerical Test on Synthetic Source Time Function}

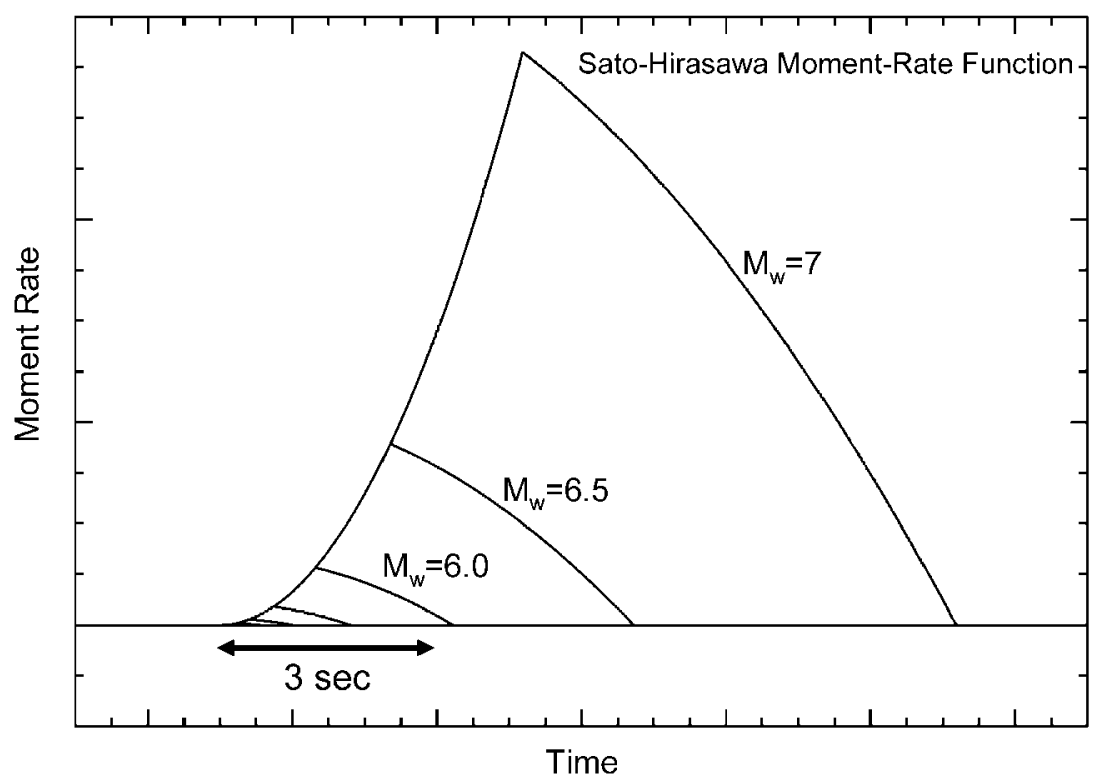

Figure 2. Displacement waveforms computed for the kinematic source model of Sato and Hirasawa (1973). The parameters used for computation of waveforms are: $P$-wave speed, $6 \mathrm{~km} / \mathrm{sec} ; S$-wave speed, $3.5 \mathrm{~km} / \mathrm{sec}$; density, $2.7 \mathrm{~g} / \mathrm{cm}^{3}$; rupture speed, $2.5 \mathrm{~km} / \mathrm{sec}$; applied shear stress, 30 bars; polar angle of the station location, $90^{\circ}$ (Kanamori, 2005).

$$
\tau_{c}=\frac{1}{\sqrt{\left\langle f^{2}\right\rangle}}=\frac{2 \pi}{\sqrt{r}}
$$

can be used as a parameter representing the period of the initial portion of the $P$ wave. The larger $\tau_{c}$ is, the larger the event is. This method is different from Nakamura's (1988) in that we compute $\tau_{c}$ using the displacement $u(t)$ over a fixed time window after the $P$-wave onset. To demonstrate that $\tau_{c}$ is a good measure of the size of an earthquake, we computed $\tau_{c}$ for the waveforms resulting from the kinematic source model of Sato and Hirasawa (1973). Figure 2 shows the displacement waveforms of Sato and Hirasawa's (1973) model, and $\tau_{c}$ computed for them using equations (1) and (3) is shown by a dashed line in Figure 3. For this particular model, $\tau_{c}$ saturates at $M_{\mathrm{w}}$ slightly larger than 6.5.

Kanamori (2005) has applied this method to available close-in records for events with $M 2.5$ to 8.0 (the 2003 Tokachi-Oki, Japan, earthquake) to determine $\tau_{c}$. As shown in Figure 3, the results are consistent with the simulation result for the model of Sato and Hirasawa (1973) shown by the dashed line. The difference in the slope is due to the difference in the source time functions between the model of Sato and Hirasawa (1973) and the real earthquakes. Somewhat surprisingly, $\tau_{c}$ keeps increasing even for earthquakes with $M>7$, without any obvious sign of saturation. Since the data set is sparse for very large events (only five earthquakes with $M \geq 7$ ), this result is not conclusive.

For the EWS application, if $\tau_{c}<1 \mathrm{sec}$, the event has already ended or is not likely to grow beyond $M>6$. If $\tau_{\mathrm{c}}>1 \mathrm{sec}$, it is likely to grow, but how large it will eventually become cannot be determined. In this sense, this method provides a threshold warning.

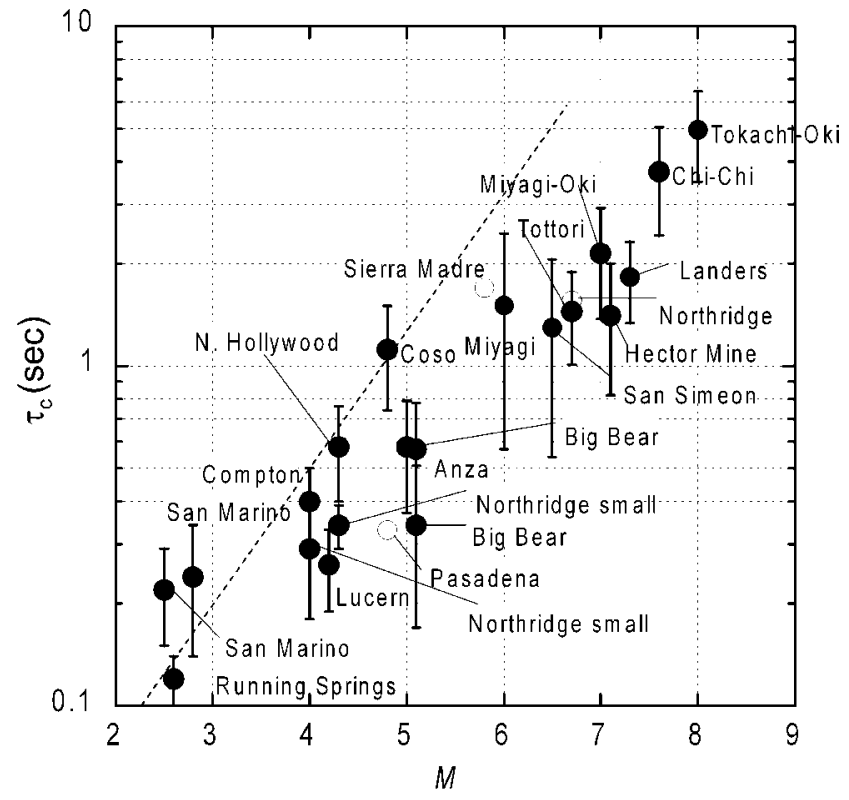

Figure 3. $\tau_{c}$ computed for earthquakes with $2.5<$ $M<8.0$ in Japan and California using close-in seismograms (Kanamori, 2005). $M$ represents $M_{\mathrm{w}}$ and $M_{\mathrm{L}}$ for $M \geq 6$, and $M<6$, respectively. Open circles indicate data points for which only one or two records were available. The error bars indicate one standard deviation.

\section{Data and Analysis}

Large and shallow earthquakes often cause the most serious damage. Thus, we selected 26 events in Taiwan for this study (Table 1). The selection criteria were $M_{\mathrm{w}}>5.0$ and focal depth $<35 \mathrm{~km}$, as listed in the Harvard catalog. 
All the events were well recorded by the Taiwan Strong Motion Instrumentation Program (TSMIP) network. These events occurred during the period from 1993 to 2003 and were widely felt in Taiwan. With about 650 modern digital accelerographs installed at free-field sites (Fig. 1a), the TSMIP station signals are digitized at 200 samples per second or higher at 16-bit resolution. Most accelerographs have a dynamic range of $\pm 2 g$.

A total of 507 TSMIP records were used for this study. They were recorded at an epicentral distance of less than 30 $\mathrm{km}$, and at least eight records were available for each event. For EWS purposes, near-source records are most important.

Vertical component strong-motion records were used in this study. Input signals were integrated twice to displacement records. We applied a 0.075-Hz high-pass Butterworth filter to remove the low-frequency drift after integration. We used an automatic $P$ picker similar to that described by Allen (1978) to detect the $P$-wave arrival from vertical acceleration records. In this study, we computed $\tau_{c}$ from the 3 -sec-long filtered displacement signals after the $P$ arrival. We also computed the peak displacement amplitude (PK3s) for the same time window for further analysis.

\section{Results}

Figure $4 \mathrm{a}$ shows $\tau_{c}$ determined from all of the 507 records plotted as a function of $M_{\mathrm{w}}$. Although $\log \tau_{c}$ increases

Table 1

Twenty-six Events Used in This Study

\begin{tabular}{|c|c|c|c|c|c|c|c|}
\hline \multirow{2}{*}{$\frac{\text { No. }}{1}$} & \multicolumn{2}{|c|}{ Origin Time (UT) } & \multirow{2}{*}{$\begin{array}{c}\begin{array}{c}\text { Lat. } \\
(\mathrm{N})\end{array} \\
23.213\end{array}$} & \multirow{2}{*}{$\begin{array}{c}\begin{array}{c}\text { Long. } \\
(\mathrm{E})\end{array} \\
120.524\end{array}$} & \multirow{2}{*}{$\begin{array}{c}\begin{array}{c}\text { Depth } \\
(\mathrm{km})\end{array} \\
12.50\end{array}$} & \multirow{2}{*}{$\begin{array}{r}M_{\mathrm{w}} \\
5.4\end{array}$} & \multirow{2}{*}{$\begin{array}{c}\begin{array}{c}\text { No. of } \\
\text { Records }\end{array} \\
26\end{array}$} \\
\hline & $1993 / 12 / 15$ & $21: 49: 43.10$ & & & & & \\
\hline 2 & $1994 / 06 / 05$ & 01:09:30.09 & 24.462 & 121.838 & 5.30 & 6.3 & 13 \\
\hline 3 & $1995 / 01 / 10$ & $07: 55: 19.56$ & 23.680 & 121.432 & 3.81 & 5.1 & 14 \\
\hline 4 & $1995 / 02 / 23$ & 05:19:02.78 & 24.204 & 121.687 & 21.69 & 6.2 & 16 \\
\hline 5 & $1995 / 05 / 27$ & $18: 11: 11.12$ & 23.008 & 121.465 & 19.73 & 5.7 & 8 \\
\hline 6 & $1995 / 12 / 18$ & $16: 17: 54.53$ & 24.018 & 121.692 & 22.06 & 5.2 & 22 \\
\hline 7 & $1996 / 11 / 26$ & $08: 22: 23.71$ & 24.164 & 121.695 & 26.18 & 5.2 & 16 \\
\hline 8 & 1998/01/18 & $19: 56: 51.71$ & 22.725 & 121.089 & 3.28 & 5.2 & 18 \\
\hline 9 & $1998 / 07 / 17$ & $04: 51: 14.96$ & 23.503 & 120.663 & 2.80 & 5.7 & 27 \\
\hline 10 & $1998 / 11 / 17$ & $22: 27: 32.52$ & 22.832 & 120.790 & 16.49 & 5.3 & 10 \\
\hline 11 & $1999 / 09 / 20$ & $17: 47: 15.85$ & 23.855 & 120.816 & 8.00 & 7.6 & 18 \\
\hline 12 & $1999 / 10 / 22$ & $02: 18: 56.90$ & 23.517 & 120.423 & 16.59 & 5.8 & 43 \\
\hline 13 & $1999 / 10 / 22$ & $03: 10: 17.46$ & 23.533 & 120.431 & 16.74 & 5.5 & 43 \\
\hline 14 & $1999 / 10 / 30$ & $08: 27: 49.50$ & 24.017 & 121.319 & 14.36 & 5.4 & 22 \\
\hline 15 & $2000 / 02 / 15$ & $21: 33: 18.15$ & 23.316 & 120.740 & 14.71 & 5.2 & 16 \\
\hline 16 & $2000 / 07 / 14$ & $00: 07: 32.46$ & 24.048 & 121.728 & 7.19 & 5.4 & 29 \\
\hline 17 & $2000 / 08 / 23$ & $00: 49: 16.58$ & 23.636 & 121.635 & 27.48 & 5.3 & 11 \\
\hline 18 & $2000 / 09 / 10$ & $08: 54: 46.53$ & 24.085 & 121.584 & 17.74 & 5.8 & 31 \\
\hline 19 & $2001 / 06 / 14$ & $02: 35: 25.78$ & 24.419 & 121.928 & 17.29 & 5.9 & 15 \\
\hline 20 & $2001 / 06 / 19$ & $05: 16: 15.46$ & 23.177 & 121.077 & 6.58 & 5.3 & 11 \\
\hline 21 & $2001 / 06 / 19$ & $05: 43: 39.17$ & 23.197 & 121.098 & 11.70 & 5.1 & 13 \\
\hline 22 & $2002 / 02 / 12$ & $03: 27: 25.00$ & 23.741 & 121.723 & 29.98 & 5.7 & 21 \\
\hline 23 & $2002 / 04 / 03$ & 18:06:10.79 & 24.322 & 121.868 & 12.87 & 5.3 & 9 \\
\hline 24 & $2002 / 05 / 15$ & 03:46:05.91 & 24.651 & 121.872 & 8.52 & 6.1 & 26 \\
\hline 25 & $2003 / 06 / 16$ & $18: 33: 38.85$ & 23.543 & 121.654 & 28.26 & 5.5 & 10 \\
\hline 26 & $2003 / 12 / 10$ & $04: 38: 13.52$ & 23.067 & 121.398 & 17.73 & 6.8 & 19 \\
\hline
\end{tabular}

approximately linearly with $M_{\mathrm{w}}$, the scatter is very large, especially for events with $M_{\mathrm{w}}<5.5$. The large scatter is primarily due to the very small displacement amplitudes, PK3s, during the first $3 \mathrm{sec}$. Figure $4 \mathrm{~b}$ shows PK3s for all of the 507 records as a function of $M_{\mathrm{w}}$. The initial amplitude PK3s is generally small for the smaller events, especially for events with $M_{\mathrm{w}}<5.5$; this results in a poor signal-to-noise

(a)

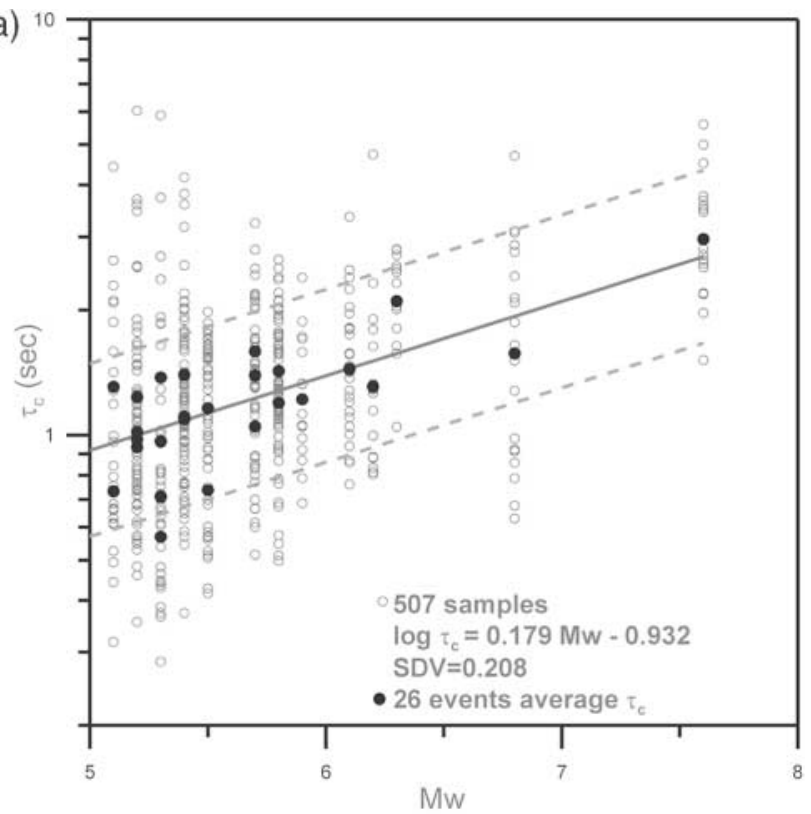

(b)

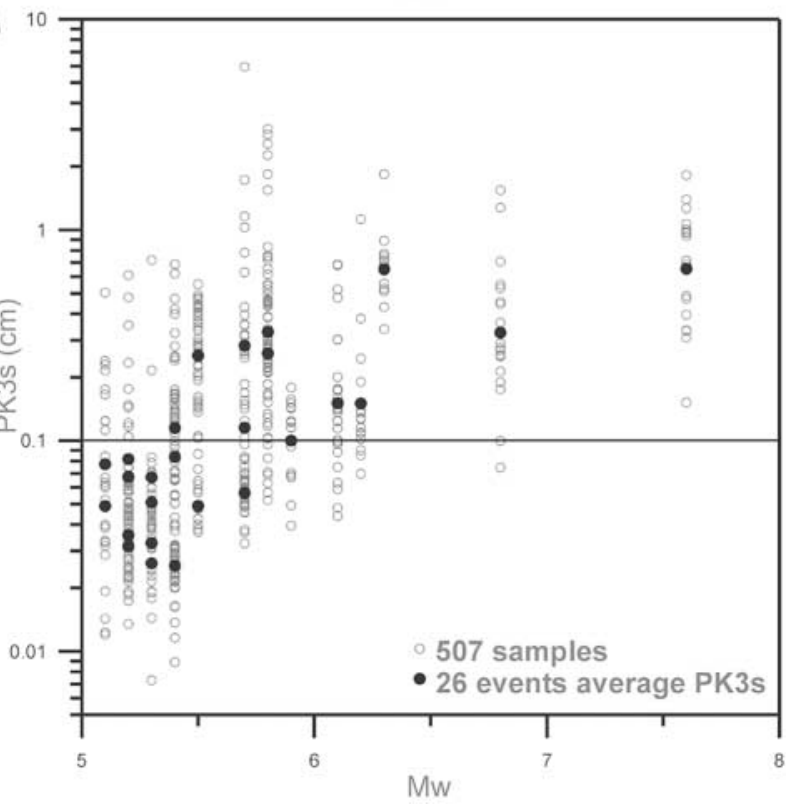

Figure 4. (a) $\tau_{c}$ measurements (open circles) from 507 strong-motion records within the epicentral distance of $30 \mathrm{~km}$ versus $M_{\mathrm{w}}$. Solid circles show the average for the 26 events listed in Table 1. (b) PK3s measurements from 507 strong-motion records within the epicentral distance of $30 \mathrm{~km}$ versus $M_{\mathrm{w}}$. Solid circles show the average for the 26 events listed in Table 1. 
ratio for $\tau_{c}$ determinations. From the EWS point of view, small-amplitude data are not of interest, and also $\tau_{c}$ needs to be determined as rapidly as possible after the $P$ wave is detected at the first station. Thus, in our experiment we removed all of the data with PK3s $<0.1 \mathrm{~cm}$ and used only the first eight stations within less than $21 \mathrm{~km}$ to determine $\tau_{c}$. Figure 5a shows the results for which the first eight records with PK3s $>0.1 \mathrm{~cm}$ are used. The determinations were made for the 12 events for which such data were available. Table 2 summarizes the results of $\tau_{c}$ determinations together with the distance to the farthest station. The relationship between the average $\tau_{c}$ and $M_{\mathrm{w}}$ is given by,

$$
\log \tau_{c}=0.221 M_{\mathrm{w}}-1.113
$$

or, conversely, by,

$$
M_{\mathrm{w}}=4.525 \log \tau_{c}+5.036
$$

The earthquakes we studied all had $M_{\mathrm{w}}>5$ and were potentially damaging; except for one earthquake, all of them (a)



(b)

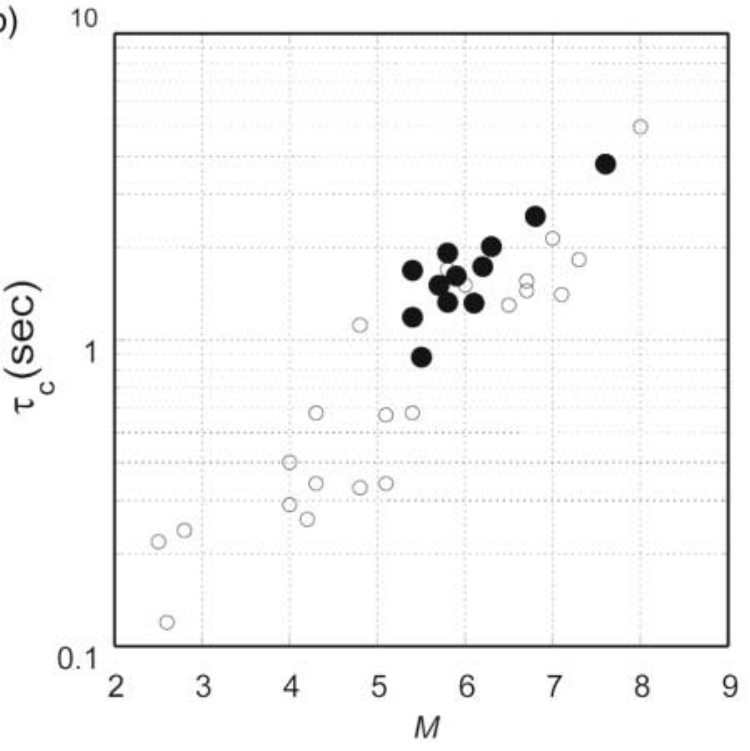

Figure 5. (a) Relationship between the averaged $\tau_{c}$ and $M_{\mathrm{w}}$ of the 12 events from the closest eight records with $\mathrm{PK} 3 \mathrm{~s}>0.1 \mathrm{~cm}$. (b) The average $\tau_{c}$ determined for the Taiwan events shown in Figure 5a (solid circles) together with those for earthquakes in Japan and California (open circles). The definition of $M$ is the same as that in Figure 3. 
Table 2

$\tau_{c}$ of 12 Events from Closest Eight Records with PK3s $>0.1 \mathrm{~cm}$

\begin{tabular}{rlllllllllll}
\hline No. & $M_{\mathrm{w}}$ & $\tau_{\mathrm{c}}$ & $\tau_{\mathrm{c}} 1$ & $\tau_{\mathrm{c}} 2$ & $\tau_{\mathrm{c}} 3$ & $\tau_{\mathrm{c}} 4$ & $\tau_{\mathrm{c}} 5$ & $\tau_{\mathrm{c}} 6$ & $\tau_{\mathrm{c}} 7$ & $\tau_{\mathrm{c}} 8$ & Dist \\
\hline 1 & 5.4 & 1.19 & 1.77 & 1.36 & 0.66 & 1.34 & 1.39 & 0.7 & 1.23 & 1.07 & 20.5 \\
2 & 6.3 & 2.02 & 1.05 & 1.64 & 1.57 & 2.79 & 1.81 & 2.71 & 2.01 & 2.55 & 19.9 \\
4 & 6.2 & 1.74 & 0.89 & 4.73 & 0.81 & 1.26 & 2.32 & 0.88 & 1.14 & 1.90 & 19.4 \\
9 & 5.7 & 1.51 & 2.10 & 1.43 & 1.01 & 2.80 & 1.62 & 1.32 & 1.15 & 0.66 & 20.1 \\
11 & 7.6 & 3.76 & 5.00 & 3.66 & 3.76 & 5.59 & 4.51 & 2.59 & 3.44 & 1.52 & 20.4 \\
12 & 5.8 & 1.93 & 2.64 & 1.88 & 2.52 & 1.52 & 2.37 & 2.40 & 0.79 & 1.35 & 20.6 \\
13 & 5.5 & 0.88 & 0.42 & 0.88 & 0.87 & 0.60 & 0.92 & 0.70 & 1.54 & 1.11 & 20.6 \\
16 & 5.4 & 1.69 & 1.89 & 1.48 & 2.09 & 2.10 & 1.36 & 1.24 & 1.33 & 2.00 & 20.4 \\
18 & 5.8 & 1.33 & 1.24 & 1.33 & 1.14 & 1.66 & 1.27 & 1.04 & 1.32 & 1.65 & 20.4 \\
19 & 5.9 & 1.62 & 1.70 & 1.05 & 1.88 & 1.58 & 1.33 & 2.39 & 1.72 & 1.33 & 20.7 \\
24 & 6.1 & 1.32 & 2.24 & 1.80 & 0.87 & 1.10 & 0.76 & 1.56 & 1.05 & 1.14 & 19.9 \\
26 & 6.8 & 2.54 & 4.70 & 3.10 & 2.76 & 3.07 & 2.86 & 0.92 & 2.14 & 0.79 & 18.2 \\
\hline
\end{tabular}

$\tau_{c}$, average value for each event unit in $\mathrm{s} ; \tau_{c} 1-8, \tau_{\mathrm{c}}$ for the closest eight stations; Dist, epicentral distance in kilometers of the eighth closest station.

had $\tau_{c}>1 \mathrm{sec}$. As shown in Figure $5 \mathrm{~b}$, this trend is consistent with that obtained for the events in Japan and California (Figure 3).

For events in California, broad-band records were used for small events, and most events with $M_{\mathrm{w}}<5$ have $\tau_{c}>1$ sec. Thus, the use of $\tau_{c}$ provides a useful threshold warning for large earthquakes. If $\tau_{c}>1 \mathrm{sec}$, the event is potentially damaging. If it is larger than $2 \mathrm{sec}$, the event is almost certainly damaging. Combining this information with other data, such as the initial velocity and displacement amplitudes, would allow the damage potential of the event to be assessed more accurately.

\section{Discussion and Conclusions}

In Taiwan, the TSMIP telemetered stations are densely distributed all over the island. If detection of the $P$ arrival and the determinations of $\tau_{c}$ and PK $3 \mathrm{~s}$ are made on-site, these parameters can be sent to the control center rapidly and reliably. By using the average of the values from the first eight stations as an indicator, earthquake early warnings can be issued rapidly. Furthermore, Internet function can now be installed at most sites, which will save much of the telemetry cost.

Figure 6 shows the travel time of $P$ and $S$ waves for a reference focal depth at $10 \mathrm{~km}$. Currently the Taiwan EWS can provide rapid reporting at $22 \mathrm{sec}$ after the event origin time by using the VSN method. The 2003 Chengkung $M_{\mathrm{w}}$ 6.8 earthquake is a representative case. The VSN system reported the information on this earthquake at $22 \mathrm{sec}$ after the occurrence with an estimated $M_{\mathrm{L}}$ of 6.5 and a good hypocenter determination. The front-detection EWS provides a warning to areas at distances greater than about $70 \mathrm{~km}$ from the epicenter (i.e., the radius of the blind zone is $70 \mathrm{~km}$ ). In our experiment on the $\tau_{c}$ method, we used $P$ waves from the strong-motion records within $21 \mathrm{~km}$ of the epicenter. Figure 6 shows that $P$ waves need about $4.5 \mathrm{sec}$ to reach 21 $\mathrm{km}$. And this method needs only $3 \mathrm{sec}$ of waveform data.

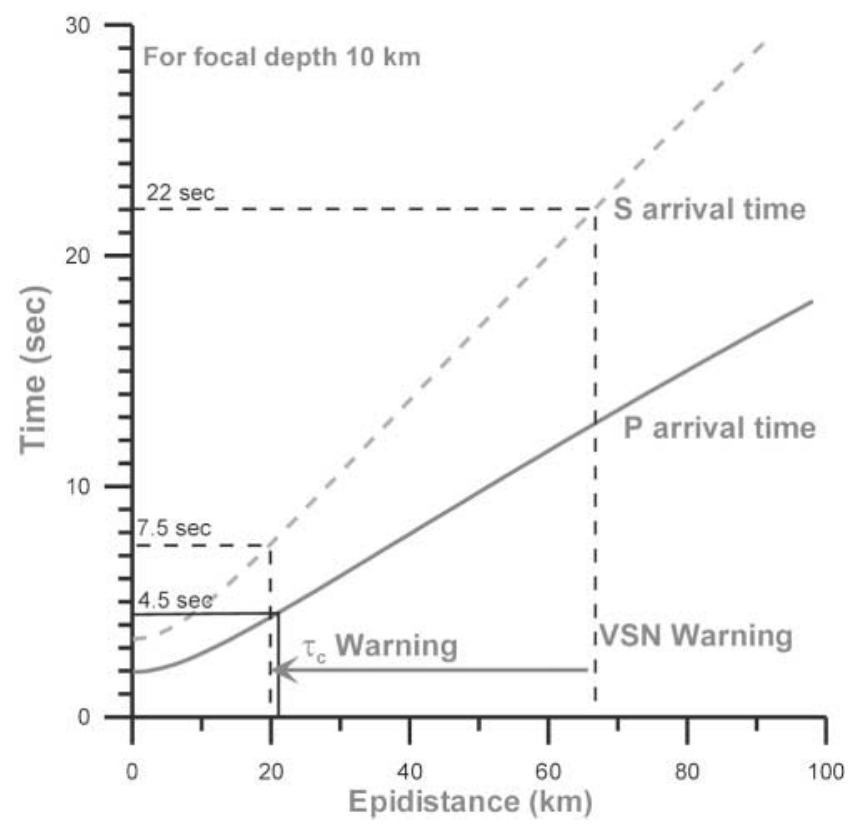

Figure 6. Rapid reporting time and warning distance of the $\tau_{c}$ and VSN methods.

Thus, the total procedure needs about $7.5 \mathrm{sec}$. At that time, $S$ waves have propagated only to about $20 \mathrm{~km}$ from the epicenter, so we can reduce the radius of the blind zone to 20 km (Fig. 1b).

Large damaging earthquakes with very large ground motions often caused interruption of telemetry within a few seconds after the onset, resulting in the loss of data. This problem caused difficulty in the traditional measurement of peak amplitude for determination of $M_{\mathrm{L}}$ and intensity. However, the $\tau_{c}$ method can overcome this difficulty because $\tau_{c}$ and PK3s are measured from the beginning of $P$ arrival, before telemetry interruption occurs.

Our experiment on the $\tau_{c}$ method using the data in the Taiwan region suggests that it is possible to determine, onsite, both $\tau_{c}$ and PK3s, which jointly give reliable threshold warnings. The $\tau_{c}$ method can reduce the radius of the blind zone to $20 \mathrm{~km}$, and it will be a useful complement to the front-detection EWS in Taiwan.

\section{Acknowledgments}

The authors wish to thank Professor Ta-liang Teng and Dr. Willie Lee for providing many thought-provoking comments. We would like to thank Dr. Yutaka Nakamura for reviewing this paper and his valuable comments. This research was supported by the Central Weather Bureau and the National Science Council of the Republic of China.

\section{References}

Allen, R. V. (1978). Automatic earthquake recognition and timing from single traces, Bull. Seism. Soc. Am. 68, 1521-1532.

Allen, R. M., and H. Kanamori (2003). The potential for earthquake early warning in Southern California, Science 300, 685-848. 
Espinosa-Aranda, J., A. Jiménez, G. Ibarrola, F. Alcantar, A. Aguilar, M. Inostroza, and S. Maldonado (1995). Mexico City seismic alert system, Seism. Res. Lett. 66, 42-53.

Grecksch, G., and H. J. Kumpel (1997). Statistical analysis of strongmotion accelerogram and its application to earthquake early-warning systems, Geophys. J. Int. 129, 113-123.

Heaton, T. H. (1985). A model for a seismic computerized alert network, Science 228, 987-990.

Kanamori, H. (2005). Real-time seismology and earthquake damage mitigation, Annu. Rev. Earth Planet. Sci. (in press).

Kanamori, H., E. Hauksson, and T. Heaton (1997). Real-time seismology and earthquake hazard mitigation, Nature 390, 461-464.

Nakamura, Y. (1984). Development of the earthquake early-warning system for the Shinkansen, some recent earthquake engineering research and practical in Japan. The Japanese National Committee of the International Association for Earthquake Engineering, 224-238.

Nakamura, Y. (1988). On the urgent earthquake detection and alarm system (UrEDAS), Proc. of the 9th World Conference on Earthquake Engineering, Tokyo-Kyoto, Japan.

Nakamura, Y. (1989). Earthquake alarm system for Japan railways, Jpn. Railway Eng. 109, 1-7.

Sato, Y., and Y. Hirasawa (1973). Body wave spectra from propagating shear cracks, J. Phys. Earth 21, 415-431.

Teng, T. L., Y. M. Wu, T. C. Shin, Y. B. Tsai, and W. H. K. Lee (1997). One minute after: strong-motion map, effective epicenter, and effective magnitude, Bull. Seism. Soc. Am. 87, 1209-1219.

United States Geological Survey (1998). A plan for implementing a realtime seismic hazard warning system. A report to Congress required by public law 105-47. 27 March 1998, Washington, D.C.

United States National Research Council (1991). Real-time earthquake monitoring, Report from the Committee on Seismology, National Academy Press, Washington, D.C., USA. 52 pp.

Wu, Y. M., and T. L. Teng (2004). Near real-time magnitude determination for large crustal earthquakes, Tectonophysics 390, 205-216.

Wu, Y. M., and T. L. Teng (2002). A virtual sub-network approach to earthquake early warning, Bull. Seism. Soc. Am. 92, 2008-2018.

Wu, Y. M., C. C. Chen, T. C. Shin, Y. B. Tsai, W. H. K. Lee, and T. L.
Teng (1997). Taiwan Rapid Earthquake Information Release System, Seism. Res. Lett. 68, 931-943.

Wu, Y. M., T. C. Shin, and Y. B. Tsai (1998). Quick and reliable determination of magnitude for seismic early warning, Bull. Seism. Soc. Am. 88, 1254-1259.

Wu, Y. M., J. K. Chung, T. C. Shin, N. C. Hsiao, Y. B. Tsai, W. H. K. Lee, and T. L. Teng (1999). Development of an integrated seismic early warning system in Taiwan-case for the Hualien area earthquakes, TAO: Terrestrial, Atmospheric and Oceanic Sciences 10, 719-736.

Wu, Y. M., W. H. K. Lee, C. C. Chen, T. C. Shin, T. L. Teng, and Y. B. Tsai (2000). Performance of the Taiwan Rapid Earthquake Information Release System (RTD) during the 1999 Chi-Chi (Taiwan) earthquake, Seism. Res. Lett. 71, 338-343.

Wu, Y. M., T. C. Shin, and C. H. Chang (2001). Near realtime mapping of peak ground acceleration and peak ground velocity following a strong earthquake, Bull. Seism. Soc. Am. 91, 1218-1228.

Wu, Y. M., N. C. Hsiao, T. L. Teng, and T. C. Shin (2002). Near real-time seismic damage assessment of the rapid reporting system, TAO: Terrestrial, Atmospheric and Oceanic Sciences 13, 313-324.

Wu, Y. M., T. L. Teng, T. C. Shin, and N. C. Hsiao (2003). Relationship between peak ground acceleration, peak ground velocity, and intensity in Taiwan, Bull. Seism. Soc. Am. 93, 386-396.

Department of Geosciences

National Taiwan University

No. 1, Sec. 4, Roosevelt Road

Taipei 106, Taiwan

drymwu@ntu.edu.tw

(Y.M.W.)

Seismological Laboratory

California Institute of Technology

Pasadena, California 91125

(H.K.)

Manuscript received 21 May 2004. 